\title{
Insulin resistance and coronary artery disease
}

\author{
P. Bressler ${ }^{1}$, S. R. Bailey ${ }^{2}$, M.Matsuda ${ }^{1}$, R.A.DeFronzo ${ }^{1}$ \\ ${ }^{1}$ Diabetes Division, University of Texas Health Science Center, San Antonio, Texas, USA \\ ${ }^{2}$ Cardiology Division, University of Texas Health Science Center, San Antonio, Texas, USA
}

Summary The purpose of the present study was to quantitate insulin-mediated glucose disposal in normal glucose tolerant patients with angiographically documented coronary artery disease (CAD) and to define the pathways responsible for the insulin resistance. We studied 13 healthy, normal weight, normotensive subjects with angiographically documented CAD and 10 age-, weight-matched control subjects with an oral glucose tolerance test and a 2-h euglycaemic insulin $\left(40 \mathrm{mU} \cdot \mathrm{m}^{-2} \cdot \mathrm{min}^{-1}\right)$ clamp with tritiated glucose and indirect calorimetry. Lean body mass was measured with tritiated water. All CAD and control subjects had a normal oral glucose tolerance test. Fasting plasma insulin concentration (66 \pm 6 vs $42 \pm 6 \mathrm{pmol} / 1, p<0.05)$ and area under the plasma insulin curve following glucose ingestion $(498 \pm 54$ vs $\left.348 \pm 42 \mathrm{pmol} \cdot 1^{-1} \cdot \mathrm{min}^{-1}, p<0.001\right)$ were increased in $\mathrm{CAD}$ vs control subjects. Insulin-mediated whole body glucose disposal $(27.8 \pm 3.9$ vs $38.3 \pm 4.4$ $\mu \mathrm{mol} \cdot \mathrm{kg}$ fat free mass $\left.(\mathrm{FFM})^{-1} \cdot \min ^{-1}, p<0.01\right)$ was significantly decreased in CAD subjects and this was entirely due to diminished non-oxidative glucose disposal $\left(8.9 \pm 2.8\right.$ vs $20.0 \pm 3.3 \mu \mathrm{mol} \cdot \mathrm{kg} \mathrm{FFM}^{-1} \cdot \mathrm{min}^{-1}$, $p<0.001)$. The magnitude of insulin resistance was positively correlated with the severity of CAD $(r=0.480, p<0.05)$. In the CAD subjects basal and insulin-mediated rates of glucose and lipid oxidation were normal and insulin caused a normal suppression of hepatic glucose production. In conclusion, subjects with angiographically documented CAD are characterized by moderate-severe insulin resistance and hyperinsulinaemia and should be included in the metabolic and cardiovascular cluster of disorders that comprise the insulin resistance syndrome or 'syndrome X'. [Diabetologia (1996) 39: 1345-1350]

Keywords Insulin resistance, coronary artery disease, glucose metabolism, hyperinsulinaemia.
During the past 10 years a number of very common metabolic and cardiovascular disorders including hypertension, dyslipidaemia (reduced HDL-cholesterol and hypertriglyceridaemia), obesity (especially visceral), non-insulin-dependent diabetes mellitus (NIDDM) and atherosclerotic cardiovascular disease

Received: 6 February 1996 and in revised form: 29 May 1996

Corresponding author: R.A.DeFronzo, MD, Diabetes Division, University of Texas Health Science Center, 7703 Floyd Curl Drive, San Antonio, TX 78284, USA

Abbreviations: CAD, Coronary artery disease; OGTT, oral glucose tolerance test; NIDDM, non-insulin-dependent diabetes mellitus; NEFA, non-esterified fatty acids; FFM, fat free mass. have been shown to be associated with hyperinsulinaemia and underlying insulin resistance [1-3]. This cluster has been referred to as the insulin resistance syndrome or 'syndrome $X$ ' [1-3]. The link between hyperinsulinaemia and hypertension [4], dyslipidaemia [5], obesity [6], and NIDDM [7, 8] appears to be well established. Because hyperinsulinaemia represents a compensatory response to an impairment in insulin action [1, 2, 7-9], it is generally assumed that underlying insulin resistance is present in all of the above conditions. Indeed, such an association has been demonstrated for hypertension, dyslipidaemia, obesity, and NIDDM [1-10]. A number of experimental studies in animals [11-13], dating back to the early 1950s, have indicated that hyperinsulinaemia also promotes atherosclerosis. An association 
between hyperinsulinaemia and atherosclerotic cardiovascular events has also been documented in large-scale epidemiologic studies in both non-diabetic [14-19] and diabetic [20-24] individuals. However, little information is available about the association between insulin resistance and atherosclerosis. Laakso et al. [25] have shown that non-diabetic subjects with asymptomatic femoral and carotid atherosclerosis are insulin resistant compared to subjects without peripheral atherosclerosis. No publications have appeared in which insulin sensitivity was measured in patients with documented coronary artery disease (CAD). The present study was, therefore, undertaken to quantitate insulin-mediated glucose disposal in normal glucose tolerant patients with angiographically documented CAD and to define the intracellular pathways responsible for the insulin resistance.

\section{Subjects and methods}

Subjects. Ten healthy control subjects without CAD and 13 subjects with angiographically documented CAD served as the subject population. Subjects who had a diagnostic cardiac catheterization within the 4-month period prior to initiation of the study, who had never been told that they were diabetic, and whose fasting glucose concentration at the time of cardiac catheterization was not diagnostic of diabetes were contacted by phone. Those individuals who expressed an interest in the study received an oral glucose tolerance test (OGTT). Six subjects with angiographically documented CAD and two without CAD were excluded because of an abnormal glucose tolerance curve. The characteristics of the two study groups are shown in Table 1.

The control and CAD groups were well matched for age, gender, race, ideal body weight, and body mass index. All subjects were within $30 \%$ of ideal body weight based upon the 1959 Metropolitan Life Insurance tables. All subjects had a normal OGTT according to National Diabetes Data Group (NDDG) criteria and, other than chest pain, all subjects were in good general health. No subject had any clinical or laboratory evidence of endocrine disease, hypertension, liver or renal disease, or any major organ system disease. In 1 subject who was taking a beta blocker, the drug was discontinued 2.5 weeks prior to study. No subject was taking a diuretic. In the CAD group 2 subjects were taking a long-acting nitrate preparation alone, 4 subjects were taking a calcium channel blocker alone, and 7 subjects were taking a calcium channel blocker plus a long-acting nitrate preparation. No subjects in the control group were taking any medication known to affect glucose metabolism. No subject was excessively sedentary or was participating in any heavy exercise. All subjects with CAD had chronic stable angina and were studied when they had unrestricted activity. All patients had maintained a constant body weight for at least 2 months prior to entry into the study.

Two to 4 months prior to entry into the study, all subjects had undergone a diagnostic cardiac catheterization as part of an evaluation for chest pain, for an abnormal stress test, or for a heart murmur. The indications for coronary arteriography in the CAD group included: chest pain plus an abnormal ECG, abnormal stress ECG test or abnormal stress-thallium test
Table 1. Clinical characteristics of the subjects

\begin{tabular}{lll}
\hline & Control subjects & CAD patients \\
\hline Number & 10 & 13 \\
Age (years) & $49 \pm 2$ & $53 \pm 3$ \\
Male/female & $6 \mathrm{M} / 4 \mathrm{~F}$ & $9 \mathrm{M} / 4 \mathrm{~F}$ \\
Race & $6 \mathrm{H} / 4 \mathrm{C}$ & $8 \mathrm{H} / 5 \mathrm{C}$ \\
Body weight $(\mathrm{kg})$ & $68.8 \pm 2.4$ & $71.0 \pm 6.3$ \\
Fat free mass $(\mathrm{kg})$ & $51.6 \pm 1.8$ & $52.2 \pm 4.6$ \\
Ideal body weight $(\%)$ & $116 \pm 5$ & $113 \pm 3$ \\
Body mass index $\left(\mathrm{kg} / \mathrm{m}^{2}\right)$ & $26.5 \pm 1.1$ & $25.7 \pm 0.7$ \\
Blood pressure $(\mathrm{mm} \mathrm{Hg})$ & $122 \pm 2 / 82 \pm 2$ & $125 \pm 2 / 83 \pm 2$ \\
Fasting glucose $(\mathrm{mmol} / 1)$ & $5.2 \pm 0.2$ & $5.3 \pm 0.1$ \\
$\quad$ Insulin $(\mathrm{pmol} / \mathrm{l})$ & $42 \pm 6$ & $66 \pm 6^{\mathrm{a}}$ \\
Triglycerides $(\mathrm{g} / \mathrm{l})$ & $1.26 \pm 0.10$ & $1.72 \pm 0.20^{\mathrm{b}}$ \\
Total-chol $(\mathrm{mmol} / \mathrm{l})$ & $5.20 \pm 0.16$ & $5.74 \pm 0.31^{\mathrm{a}}$ \\
LDL-chol $(\mathrm{mmol} / \mathrm{l})$ & $3.47 \pm 0.13$ & $3.78 \pm 0.26$ \\
HDL-chol $(\mathrm{mmol} / \mathrm{l})$ & $1.03 \pm 0.08$ & $1.09 \pm 0.08$ \\
\hline
\end{tabular}

${ }^{\mathrm{a}} p<0.05 ;{ }^{\mathrm{b}} p<0.01$

C, Caucasian; CAD, coronary artery disease; H, Hispanic

$(n=13)$. The indications for coronary arteriography in the control group included chest pain plus an abnormal ECG or stress-thallium test $(n=8)$ and heart murmur $(n=2)$. Cardiac catheterization was performed with the standard Judkins technique, using 6 or 7 French diagnostic catheters. Multiple orthogonal views were obtained of both the left and right coronary arteries and biplane left ventriculography was performed using a Phillips DCI system (Phillips Corp, Einthoven, The Netherlands). Coronary cineangiography was analysed using an on-line commercially available software program to determine the percentage of coronary stenosis. A subject was considered to have no CAD if no major vessel demonstrated any stenosis greater than $10 \%$. CAD was defined as the presence of stenosis greater than or equal to $50 \%$ in one or more major coronary arteries. Subjects with intermediate degrees of stenosis were excluded from the study. The subjects without significant coronary artery stenosis were considered to have non-cardiac chest pain and did not receive any specific treatment by their physicians.

Prior to their participation in the study all subjects gave their informed, written, voluntary consent. The protocol was approved by the Institutional Review Board of the University of Texas Health Science Center.

Study protocol. Each subject participated in two studies which were performed 3 to 7 days apart. All studies were carried out at $08.00 \mathrm{~h}$ after a $10-12 \mathrm{~h}$ overnight fast. On the first study day the patients underwent a 75-g OGTT. Blood samples for determination of plasma insulin, non-esterified fatty acid (NEFA), and glucose concentrations were drawn at $-30,-15,0 \mathrm{~min}$ and every $15 \mathrm{~min}$ for $2 \mathrm{~h}$. On the day of the OGTT a $100-\mu \mathrm{Ci}$ intravenous bolus injection of ${ }^{3} \mathrm{H}_{2} \mathrm{O}$ was given at time zero and blood samples were obtained at 90,105, and $120 \mathrm{~min}$ to determine lean body mass [26]. Only subjects with a normal glucose tolerance test, according to the NDDG criteria, participated in the second study. Subjects with overt diabetes or impaired glucose tolerance were excluded from further participation. Within 3-7 days following the OGTT, subjects received a hyperinsulinaemic $\left(40 \mathrm{mU} \cdot \mathrm{m}^{-2} \cdot \mathrm{min}^{-1}\right)$ euglycaemic clamp to measure whole body insulin-mediated glucose disposal [27]. The insulin infusion rate was chosen to attain physiological levels of hyperinsulinaemia ( $480 \mathrm{pmol} / \mathrm{l})$. The insulin clamp was performed with $3-{ }^{3} \mathrm{H}$-glucose, which was given as a $25-\mu \mathrm{Ci}$ bolus followed by continuous infusion at a rate of $0.25 \mu \mathrm{Ci} / \mathrm{min}$. The $3-{ }^{3} \mathrm{H}$-glucose infusion was started $120 \mathrm{~min}$ prior to the 
start of insulin infusion and maintained throughout the $2 \mathrm{~h}$ period of insulin infusion. After the start of insulin an exogenous infusion of $20 \%$ D-glucose was begun and periodically adjusted based upon the negative feedback principle to maintain euglycaemia in all patients [27]. During the $30 \mathrm{~min}$ prior to the start of the insulin infusion, five baseline blood samples were drawn for glucose, insulin, and NEFA concentrations and $3-{ }^{3} \mathrm{H}$-glucose radioactivity. During the insulin clamp period blood samples were obtained every $5-15 \mathrm{~min}$ for the determination of insulin, glucose and NEFA concentrations and $3-{ }^{3} \mathrm{H}$-glucose radioactivity. Continuous indirect calorimetry was performed during the last $45 \mathrm{~min}$ of the basal and insulin infusion periods to determine whole body rates of glucose and lipid oxidation [28]. Urine samples were collected during the $2 \mathrm{~h}$ baseline and insulin infusion periods for the determination of urea nitrogen excretion.

Analytical methods. Plasma glucose was determined by the glucose oxidase method (Beckman Glucose Analyzer, Beckman Instruments, Fullerton, Calif., USA). Plasma insulin (Coat-ACount; Diagnostic Products Corp., Los Angeles, Calif., USA) concentration was measured by radioimmunoassay. Plasma NEFA concentration was determined by a microfluorimetric method [29]. Plasma $3-{ }^{3} \mathrm{H}$-glucose radioactivity was determined following precipitation of plasma proteins with the Somogyi procedure [30].

Calculations. During the last $30 \mathrm{~min}$ of the basal period a steady-state plateau of $3-{ }^{3} \mathrm{H}$-glucose specific activity (dpm/ $\mathrm{mg}$ ) was achieved in all subjects. Hepatic glucose production (which equals the rate of glucose disposal) was determined by dividing the $3-{ }^{3} \mathrm{H}$-glucose infusion rate $(\mathrm{dpm} / \mathrm{min})$ by the steady-state glucose specific activity $(\mathrm{dpm} / \mathrm{mg})$. During the insulin period non-steady-state conditions exist and Steele's equation was used to determine whole body glucose appearance ( $\mathrm{Ra}$ ) [31]. The rate of hepatic glucose production during the insulin period was calculated by subtracting the rate of exogenous glucose infusion from the rate of total glucose appearance ( $\mathrm{Ra}$ ) determined by the isotope tracer technique. Total body glucose uptake $\left(\mu \mathrm{mol} \cdot \mathrm{kg}^{-1} \cdot \mathrm{min}^{-1}\right)$ was calculated as the sum of the exogenous glucose infusion rate plus the rate of residual hepatic glucose production. Glucose and lipid oxidation were determined from the non-protein respiratory quotient [29] obtained during the last $40 \mathrm{~min}$ of both the basal and insulin periods. Non-oxidative glucose disposal, an index of glycogen formation [32], was calculated as the difference between whole body glucose metabolism and glucose oxidation. The total body water volume was determined by dividing the dose of ${ }^{3} \mathrm{H}_{2} \mathrm{O}$ injected (dpm) by the plasma ${ }^{3} \mathrm{H}_{2} \mathrm{O}$ radioactivity $(\mathrm{dpm} / \mathrm{ml})$. The total body water is assumed to be $72 \%$ of the lean body mass. The area under the glucose and insulin curves was determined using the trapezoidal rule.

\section{Statistical analysis}

All data are presented as the mean \pm SEM. Comparison between groups was done using the Student's unpaired $t$-test. Changes from baseline within each group were determined with the paired $t$-test. Correlation coefficients were calculated using standard formulae. When comparing insulin-mediated glucose disposal with the severity of CAD, the number of stenotic coronary vessels was taken as a continuous variable. A $p$-value less than 0.05 was considered to be statistically significant.

\section{Results}

The control and CAD groups were well-matched for age, body weight, body mass index (BMI), and fat free mass (FFM) (Table 1). The fasting glucose concentration was similar in both groups, but the fasting plasma insulin concentration was significantly increased $(p<0.05)$ in patients with CAD. The total cholesterol was slightly higher in the CAD group $(p<0.05)$, but the LDL cholesterol was similar in both groups. The plasma triglyceride concentration was $37 \%$ higher in patients with CAD $(p<0.01)$, while the plasma HDL-cholesterol was similar in the two groups.

During the OGTT the plasma glucose concentration at each time point (Fig. 1), as well as the area under the glucose concentration curves $(8.1 \pm 0.2$ vs $8.0 \pm 0.2 \mathrm{mmol} \cdot \mathrm{1}^{-1} \cdot \mathrm{min}^{-1}$, respectively), were similar in the CAD and control groups. At each time point during the OGTT, the plasma insulin concentration was increased in the CAD group (Fig.1) and the area under the plasma insulin curve $(498 \pm 54$ vs $348 \pm 42 \mathrm{pmol} \cdot \mathrm{l}^{-1} \cdot \mathrm{min}^{-1}, \quad$ respectively, $\left.\quad p<0.001\right)$ was significantly increased in the CAD vs control group. Fasting plasma NEFA levels were similar in the control and CAD group and suppressed similarly during the OGTT.

During the insulin clamp the steady-state plasma glucose $(5.1 \pm 0.1$ vs $5.1 \pm 0.1 \mathrm{mmol} / \mathrm{l})$ and insulin $(534 \pm 36$ vs $462 \pm 30 \mathrm{pmol} / \mathrm{l})$ concentrations were similar in the control and CAD groups, respectively. The coefficients of variation in plasma glucose and insulin concentrations during the insulin clamp were less than 5 and $10 \%$, respectively, in all subjects. In response to insulin the increase in total body glucose disposal was significantly reduced in CAD vs control subjects $(27.8 \pm 3.9$ vs $38.3 \pm$ $4.4 \mu \mathrm{mol} \cdot \mathrm{kg} \mathrm{FFM}^{-1} \cdot \mathrm{min}^{-1}, p<0.001$ ) (Fig. 2). There was no difference in the rate of insulin-mediated glucose disposal between the eight Mexican-American and the five Caucasian subjects with CAD. Basal glucose oxidation was similar in the CAD and control groups $(9.4 \pm 0.6$ vs $8.9 \pm 0.6 \mu \mathrm{mol} \cdot \mathrm{kg}$ $\left.\mathrm{FFM}^{-1} \cdot \mathrm{min}^{-1}\right)$ and rose similarly in response to insulin $\left(18.9 \pm 2.2\right.$ vs $\left.18.3 \pm 0.6 \mu \mathrm{mol} \cdot \mathrm{kg} \mathrm{FFM}{ }^{-1} \cdot \mathrm{min}^{-1}\right)$ (Fig.2). All of the defect in insulin-mediated whole body glucose disposal in the CAD group was accounted for by a decrease in non-oxidative glucose disposal $\left(8.9 \pm 2.8\right.$ vs $20.0 \pm 3.3 \mu \mathrm{mol} \cdot \mathrm{kg} \mathrm{FFM}^{-1}$. $\min ^{-1}, p<0.001$ ) (Fig. 2).

Basal lipid oxidation was slightly greater in the CAD group vs the control group $(1.20 \pm 0.08$ vs $\left.1.06 \pm 0.09 \mathrm{mg} \cdot \mathrm{kg} \mathrm{FFM}{ }^{-1} \cdot \mathrm{min}^{-1}, p=\mathrm{NS}\right)$ and was suppressed less in the CAD vs the control group $(0.71 \pm 0.10$ vs $0.31 \pm 0.04, p<0.05)$ during the insulin clamp. Suppression of plasma NEFA concentration was slightly less in the CAD group vs the control group $(127 \pm 13$ vs $118 \pm 31 \mu \mathrm{mol} / \mathrm{l}, p=\mathrm{NS})$. 

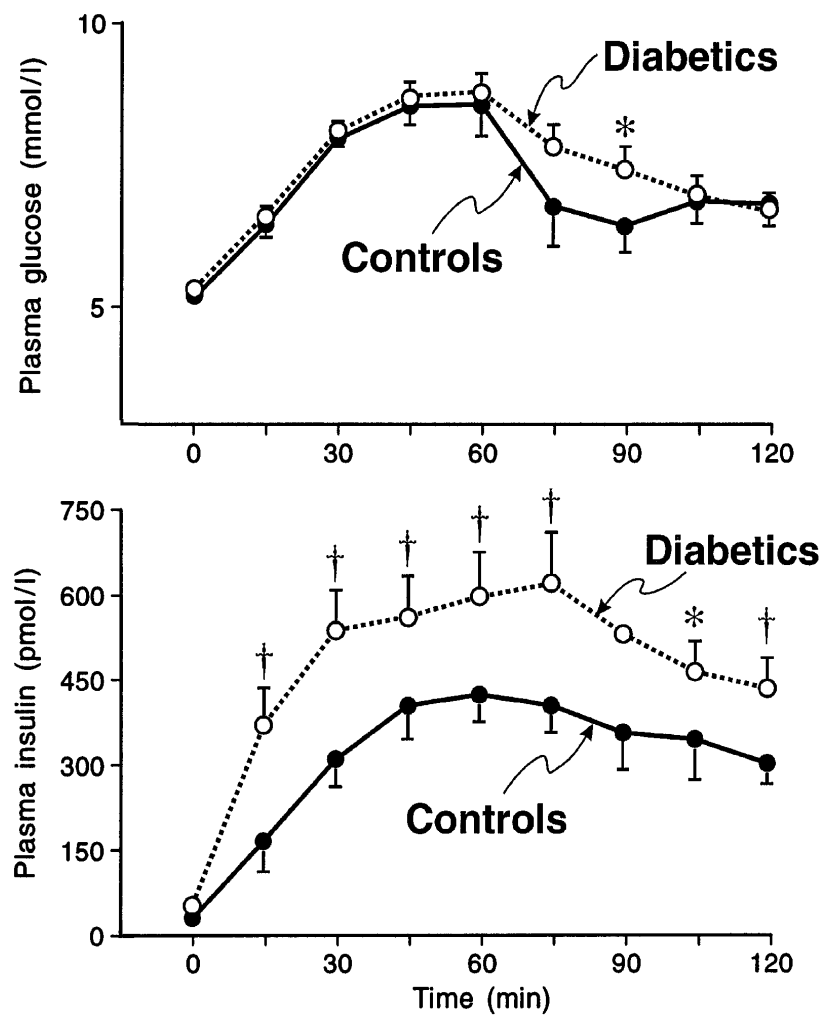

Fig. 1. Plasma glucose and insulin concentrations during the OGTTs performed in control subjects and in individuals with coronary artery disease (CAD). $* p<0.05 ; \dagger p<0.01$

During the post-absorptive state basal hepatic glucose production was similar in the control and CAD groups $\left(15.0 \pm 0.6\right.$ vs $14.4 \pm 0.6 \mu \mathrm{mol} \cdot \mathrm{kg} \mathrm{FFM}^{-1}$. $\mathrm{min}^{-1}$ ) and suppressed similarly in response to insulin $\left(0.6 \pm 0.6\right.$ vs $\left.1.1 \pm 1.1 \mu \mathrm{mol} \cdot \mathrm{kg} \mathrm{FFM}^{-1} \cdot \mathrm{min}^{-1}\right)$.

In the CAD group the rate of insulin-mediated glucose disposal was inversely related to the BMI $(r=$ $-0.648, p<0.01)$. A similar inverse relationship was noted in the control subjects $(r=-0.774, p<0.01)$. However, for any given BMI, the CAD subjects metabolized approximately $30 \%$ less glucose in response to insulin compared to the control subjects. In the CAD group the fasting plasma insulin concentration was inversely related to the rate of insulin-mediated glucose disposal $(r=-0.517, p<0.01)$ and to the $\operatorname{BMI}(r=-0.473, p<0.01)$. The area under the insulin curve was also inversely related to the rate of insulinmediated glucose disposal $(r=-0.479, p<0.01)$ but not to the BMI. An inverse relationship between the rate of insulin-mediated glucose disposal and the plasma triglyceride concentration was present in the CAD group $(r=-0.512, p<0.01)$. Similar correlations were not present in the control group. The magnitude of insulin resistance was correlated with the number of stenotic vessels $(r=0.480, p<0.05)$ (Fig. 3). No correlation was observed between the rate of insulin-mediated glucose metabolism and either the fasting or glucose-stimulated plasma insulin concentration.

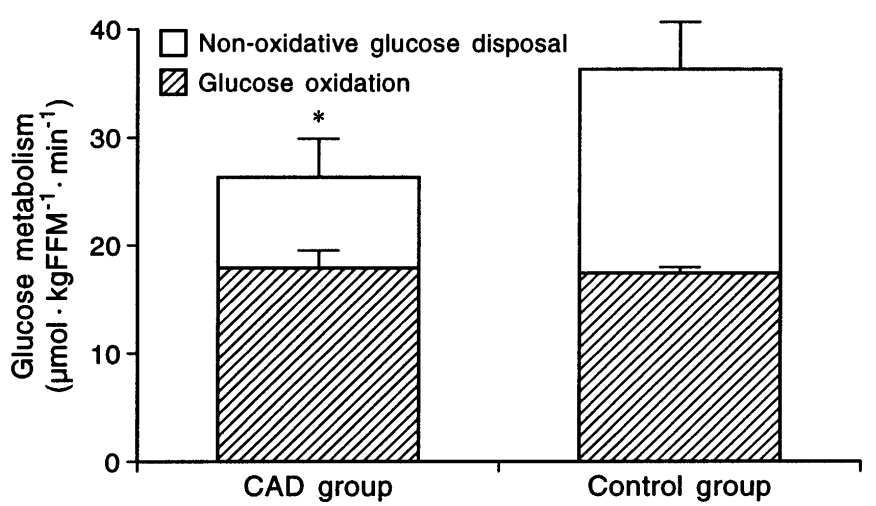

Fig. 2. Whole body glucose disposal (total height of bar), glucose oxidation (cross hatched portion of the bar) and non-oxidative glucose disposal (open portion of the bar) during the insulin clamp in control subjects and in individuals with coronary artery disease (CAD). $* p<0.001$

\section{Discussion}

The association between hypertension, dyslipidaemia, obesity, impaired glucose tolerance, NIDDM, coronary artery disease, insulin resistance and hyperinsulinaemia is well-established and collectively these disorders have been referred to as the insulin resistance syndrome or 'syndrome $X$ ' [1-3]. Of this cluster of disorders the association between atherosclerosis and insulin resistance is least well-established. Several large prospective, as well as cross-sectional, epidemiologic studies have documented an association between CAD and hyperinsulinaemia in both non-diabetic [14-19] and diabetic individuals [20-24]. An association between abnormal ECG findings and both fasting and post-OGTT plasma insulin concentrations has also been demonstrated in hypertensive non-diabetic subjects [33]. Because hyperinsulinaemia usually reflects underlying insulin resistance [1, 2, 7-9], it generally has been assumed that individuals with CAD are insulin resistant. Only one previous study, that of Laakso et al. [25], has examined insulin-mediated glucose disposal in subjects with well-documented atherosclerosis. Using ultrasonography, these investigators demonstrated an association between asymptomatic peripheral (carotid and femoral) atherosclerosis and insulin resistance in 30 middle-aged non-obese individuals. Since neither fasting nor glucose-stimulated plasma insulin levels were increased, the authors concluded that insulin resistance, and not hyperinsulinaemia, played the primary role in the development of atherosclerosis.

To our knowledge, however, no previous study has directly quantitated insulin-mediated glucose disposal and related it to the presence or absence of angiographically documented CAD. In the present study we measured insulin sensitivity with the euglycaemic insulin clamp technique and related it to the 


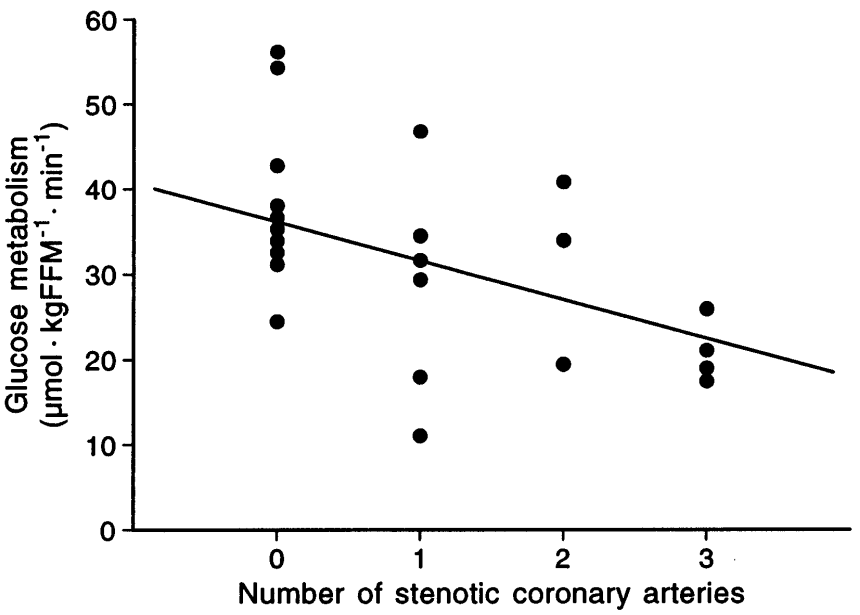

Fig. 3. Relationship between the rate of insulin-mediated glucose metabolism and the number of stenotic coronary arteries $(r=0.480, p<0.05)$

presence or absence of angiographically documented CAD. A positive relationship was observed between the severity of CAD and the severity of insulin resistance (Fig. 3). Patients with CAD had a $25 \%$ decrease in insulin sensitivity and all of the decrease in insulin action could be accounted for by a defect in non-oxidative glucose disposal (Fig.2). This pattern of insulin resistance closely resembles that which is seen in hypertension [1,4], obesity [10], NIDDM $[7,8]$, and dyslipidaemia $[5,34]$ and provides further support for the inclusion of atherosclerotic cardiovascular disease in the cluster of disorders that comprise the insulin resistance syndrome. Since the present study was carried out on a relatively modest sample size, it needs to be confirmed in larger populations. However, because of the invasive criteria used to establish the diagnosis of CAD, these studies will probably have to employ non-invasive tests to establish the diagnosis of CAD, as in the study of Paolisso et al. [35]. Using clinical and electrocardiographic criteria to establish the presence or absence of CAD, these investigators also demonstrated that patients with CAD were resistant to insulin compared to the control group.

It should be noted that our patients with CAD were not obese, had normal glucose tolerance, were normotensive, and had normal LDL-cholesterol and HDL-cholesterol levels. Therefore, we can exclude these factors in the pathogenesis of both the insulin resistance and CAD. We did not measure LDL particle size or density. Since small, dense LDL have been shown to be associated with insulin resistance and with CAD [36], a similar relationship cannot be excluded in the present study. The plasma triglyceride levels were increased in our insulin-resistant patients with CAD and, since hypertriglyceridaemia has been associated with both insulin resistance $[5,34]$ and CAD $[37,38]$, an aetiologic role for impaired VLDL metabolism in both insulin resistance and CAD cannot be excluded in the present study.

In the present study our insulin-resistant patients with CAD were also hyperinsulinaemic and, therefore, differ from the normoinsulinaemic patients described by Laakso et al. [25]. Since in vivo [11-13, $39,40]$ and in vitro $[1,41]$ studies have demonstrated that insulin is an atherogenic hormone, it is difficult to differentiate whether it is the hyperinsulinaemia or the insulin resistance that is responsible for the development of CAD. We failed to observe a significant relationship between the plasma insulin concentration and the severity of CAD. This observation suggests that it is the insulin resistance (Fig. 3), and not the level of hyperinsulinaemia, that is related to the presence of coronary atherosclerosis.

The present results may have direct clinical relevance for the treatment of diabetic patients with hypertension. Four studies have demonstrated that hypertensive non-insulin-dependent diabetic (NIDDM) patients treated with diuretics and beta blockers have an increased incidence of morbidity and mortality from atherosclerotic cardiovascular disease compared to hypertensive diabetic patients receiving no treatment or treated with other classes of antihypertensive medications [42-45]. Both beta blockers and diuretics have been shown to cause insulin resistance [46, 47]. A failure to observe the expected decline in cardiovascular morbidity and mortality has also been observed in non-diabetic hypertensive individuals treated with beta blockers and diuretics [48]. Based upon the results of the present study, it is interesting to speculate that the development of insulin resistance during beta blocker and diuretic therapy offsets the beneficial effects of these drugs in reducing the elevated blood pressure. This deleterious effect of the beta blockers and diuretics appears to be particularly pronounced in NIDDM subjects who are characterized by underlying insulin resistance.

In summary, the present results demonstrate for the first time that individuals with angiographically documented CAD are characterized by insulin resistance involving the non-oxidative or glycogen synthetic pathway. As such, these individuals closely resemble patients with essential hypertension, obesity, impaired glucose tolerance, NIDDM, and dyslipidaemia and this justifies their inclusion in the insulin resistance syndrome.

Acknowledgements. The authors wish to thank the nursing staff of the General Clinical Research Center at the Audie L. Murphy Veteran's Memorial Hospital, San Antonio, Texas for assistance in carrying out the study protocol and for the care of our patients. We also are grateful to Ms. L. Olivarri and Ms. R. Ramos-Echandi for skillful assistance in the preparation of the manuscript. This work was supported in part by GCRC grant M01-RR-01346, NIH grant AM24092, and funds from the VA Medical Research Center and the GRECC. 


\section{References}

1. DeFronzo RA, Ferrannini E (1991) Insulin resistance. A multifaceted syndrome responsible for NIDDM, obesity, hypertension, dyslipidemia, and atherosclerotic cardiovascular disease. Diabetes Care 14: 173-194

2. Reaven GM (1988) Banting Lecture. Role of insulin resistance in human disease. Diabetes 37: 1595-1607

3. Ferrannini E, Haffner SM, Mitchell BD, Stern MP (1991) Hyperinsulinaemia: the key feature of a cardiovascular and metabolic syndrome. Diabetologia 34: 416-422

4. Ferrannini E, Buzzigoli G, Bonadonna R (1987) Insulin resistance in essential hypertension. N Engl J Med 317: 350-357

5. Reaven GM (1991) Insulin resistance, hyperinsulinemia, hypertriglyceridemia, and hypertension: parallels between human disease and rodent models. Diabetes Care 14: 195-202

6. Stern MP, Haffner SM (1986) Body fat distribution and hyperinsulinemia as risk factors for diabetes and cardiovascular disease. Arteriosclerosis 6: 123-130

7. DeFronzo RA (1988) Lilly Lecture. The triumvirate: beta cell, muscle, liver. A collusion responsible for NIDDM. Diabetes 37: 667-687

8. DeFronzo RA, Bonadonna RC, Ferrannini E (1992) Pathogenesis of NIDDM. A balanced overview. Diabetes Care 15: 318-368

9. Reaven GM, Hollenbeck CB, Chen Y-Di (1989) Relationship between glucose tolerance, insulin secretion and insulin action in nonobese individuals with varying degrees of glucose tolerance. Diabetologia 32: 52-55

10. Bonora E, Del Prato S, Bonadonna RC (1992) Total body fat content and fat topography are associated differently with in vivo glucose metabolism in nonobese and obese nondiabetic women. Diabetes 41: 1151-1159

11. Cruz AB, Amatuzio DS, Grande F, Hay LJ (1961) Effect of intraarterial insulin on tissue cholesterol and fatty acids in alloxan-diabetic dogs. Circ Res 9: 39-43

12. Duff GL, McMillan GC (1949) The effect of alloxan diabetes on experimental cholesterol atherosclerosis in the rabbit. I. The inhibition of experimental cholesterol atherosclerosis in alloxan diabetes. II The effect of alloxan diabetes on the retrogression of experimental cholesterol atherosclerosis. J Exp Med 89: 611-629

13. Stamler J, Pick R, Katz LN (1960) Effect of insulin in the induction and regression of atherosclerosis in the chick. Circ Res 8: 572-576

14. Welborn JA, Wearne K (1979) Coronary heart disease incidence and cardiovascular mortality in Busselton with reference to glucose and insulin concentrations. Diabetes Care 2: 154-160

15. Fontbonne A, Charles MA, Thibult N (1991) Hyperinsulinaemia as a predictor of coronary heart disease mortality in a healthy population: the Paris Prospective Study, 15-year follow-up. Diabetologia 34: 356-361

16. Pyörälä K, Savolainen E, Kaukola S, Haapakoski J (1985) Plasma insulin and coronary heart disease risk factor relationship to other risk factors and predictive value during $9 \frac{1}{2} / 2$-year follow-up of the Helsinki Policemen Study population. Acta Med Scand 701 [Suppl] 38-52

17. Yarnell JWG, Sweetnam PM, Marks V, Teale JD, Bolton CH (1994) Insulin in ischaemic heart disease: are associations explained by triglyceride concentrations. The Caerphilly prospective study. $\mathrm{Br}$ Heart J 171: 293-296

18. Despres JP, Lamarche B, Mauriege P et al. (1996) Hyperinsulinemia as an independent risk factor for ischemic heart disease. NEJM 334: 952-957

19. McKeigue PM, Ferrie JE, Pierpoint T, Marmot MG (1993) Association of early-onset coronary heart disease in South Asian men with glucose intolerance and hyperinsulinemia. Circulation 87: 152-161

20. Turner RC (1985) United Kingdom prospective diabetes study. III. Prevalence of hypertension and hypotensive therapy in patients with newly diagnosed diabetes. Hypertension 7 [Suppl II]: 8-13

21. Pyörälä K, Uusitupa M, Laakso M, Siitonen O, Niskanen L, Ronnemaa T (1987) Macrovascular complications in relation to hyperinsulinaemia in non-insulin-dependent diabetes mellitus. Diabetes Metab 13: 345-349 Rev

22. Hillson RM, Hockaday TD, Mann JI, Newton DJ (1984) Hyperinsulinaemia is associated with development of electrocardiographic abnormalities in diabetics. Diabetes Res 1: 143-149

23. Standl E, Janka HU (1985) High serum insulin concentrations in relation to other cardiovascular risk factors in macrovascular disease of type 2 diabetes. Horm Metab Res 15 [Suppl]: 46-51
24. Ronnemaa T, Laakso M, Pyörälä K, Kallio V, Puukka P (1991) High fasting plasma insulin as an indicator of coronary heart disease in non-insulin-dependent diabetic patients and nondiabetic subjects. Arterioscler Throm 11: 80-90

25. Laakso M, Sarlund H, Salonen R et al. (1991) Asymptomatic atherosclerosis and insulin resistance. Arterioscler Throm 11: 1068-1076

26. Coleman TG, Manning RD Jr, Norman RA Jr, Guyton AC (1972) Dynamics of water-isotope distribution. Am J Physiol 223: 13711375

27. DeFronzo RA, Tobin JD, Andres R (1979) Glucose clamp technique: a method for quantifying insulin secretion and resistance. Am J Physiol 232: E214-E223

28. Simonson DC, DeFronzo RA (1990) Indirect calorimetry: methodological and interpretative problems. Am J Physiol 258: E399-E412

29. Miles JR, Glassock J, Aikens J, Gerich J, Haymond M (1983) A microfluorimetric method of free fatty acid in plasma. J Lipid Res 24: 96-99

30. Somogyi M (1930) A method for the preparation of blood filtrates for the determination of sugar. J Biol Chem 86: 655-663

31. Steele R, Wall JS, DeBodo RC, Altszuler N (1956) Measurement of size and turnover rate of body glucose pool by the isotope dilution method. Am J Physiol 187: 15-25

32. Shulman GI, Rothman DI, Jue T, Stein P, DeFronzo RA, Shulman RG (1990) Quantitation of muscle glycogen synthesis in normal subjects and subjects with non-insulin dependent diabetes by ${ }^{13} \mathrm{C}$ nuclear magnetic resonance spectroscopy. NEJM 322: 223-228

33. Sheu WH-H, Jeng C-Y, Shieh S-M et al. (1992) Insulin resistance and abnormal electrocardiograms in patients with high blood pressure. Am J Hypertens 5: 444-448

34. Tobey TA, Greenfield M, Kraemer F, Reaven GM (1981) Relationship between insulin resistance, insulin secretion, very low density lipoprotein kinetics and plasma triglyceride levels in normotriglyceridemic man. Metabolism 30: 165-171

35. Paolisso G, Gambardella A, Galzerano D et al. (1993) Metabolic features of patients with and without coronary heart disease but with a superimposable cluster of cardiovascular risk factors. Cor Art Dis 4: 1085-1091

36. Reaven GM, Chen Y-DI, Jeppesen J, Maheaux P, Krauss RM (1993) Insulin resistance and hyperinsulinemia in individuals with small, dense low density lipoprotein particles. J Clin Invest 92: 141-146

37. Aberg H, Lithell H, Selinius I, Hedstrand H (1985) Serum triglycerides are a risk factor for myocardial infarction but not for angina pectoris: results from a 10-year follow-up of Uppsala primary prevention study. Atherosclerosis 54: 89-97

38. Castelli WP (1986) The triglyceride issue: A view from Framingham. Am Heart J 112: 432-437

39. Falholt K, Cutfield R, Alejandro R, Heding L, Mintz D (1985) The effects of hyperinsulinemia on arterial wall and peripheral muscle metabolism in dogs. Metabolism 34: 1146-1149

40. Sato Y, Shiraishi S, Oshida Y, Ishiguro T, Sakamoto N (1989) Experimental atherosclerosis-like lesions induced by hyperinsulinism in Wistar rats. Diabetes 38: 91-96

41. Stout RW (1991) Insulin as a mitogenic factor: role in the pathogenesis of cardiovascular disease. Am J Med 90: 62S-65S

42. Kannel WB, Neaton JD, Wentworth D et al. (1986) Overall and coronary heart disease mortality rates in relation to major risk factors in 325,348 men screened for the MRFIT. Am Heart J 112: 825-836

43. Warram JH, Laffel LMB, Valsania P, Christlieb AR, Krowlewski AS (1991) Excess mortality associated with diuretic therapy in diabetes mellitus. Arch Int Med 151: 1350-1356

44. Klein R, Moss SE, Klein BE, De Mets DL (1989) Relation of ocular and systemic factors to survival in diabetes. Arch Int Med 149: 266272

45. Kuller LH, Hulley SB, Cohen JD, Neaton J (1986) Unexpected effects of treating hypertension in men with electrocardiographic abnormalities: a critical analysis. Circulation 73: 114-123

46. Bressler P, DeFronzo RA (1994) Drugs and diabetes. Diabetes Reviews 2: 53-84

47. Lithell HO (1991) Effect of antihypertensive drugs on insulin, glucose, and lipid metabolism. Diabetes Care 14: 203-209

48. Collins R, Peto R. MacMahon S et al. (1990) Blood pressure, stroke and coronary heart disease. Part II: Effects of short-term reductions in blood pressure - an overview of the unconfounded randomized drug trials in an epidemiological context. Lancet 335: 827-838 